\title{
HIGH PERFORMANCE RE-TM ALLOY TARGET FOR MO DISK PRODUCTION
}

\author{
K. MAKI, T. MORIMOTO, I. ANDOH, S. ENDOH, \\ Central Res. Lab., Sumitomo Metal Mining Co. Ltd. \\ 3-18-5 Nakakokubun, Ichikawa, Chiba 272, Japan
}

S. TAKAGI and T. SAKURAI

Anelva Corporation

5-1-8 Yotuya, Fuchu, Tokyo 183, Japan

\begin{abstract}
Three types of sputtering targets are intercompared when used in conjunction with an improved cathode structure. A Type B target, which is composed of elemental $\mathrm{Tb}$ and a Tb-Transition metal intermetallic compound, was found to possess superior performance characteristics, i.e. compositional uniformity, compositional stability and waste ratio.

In addition, it was deduced from finite element calculations that good cathode design is also essential to obtain optimum performance from a low magnetization target.

KEYWORDS: EROSION, MOD, SPUTTERING, STABILITY, TARGET, UNIFORMITY
\end{abstract}

\section{INTRODUCTION}

Magneto optical recording disks(MOD) are generally mass produced by magnetron sputtering of rare earth(RE)-transition metal(TM) alloy targets. It is well known that the selection of an optimal target significantly affects the performance of the MOD. These targets can be classified into three metallurgical categories. As described in Table 1, Type A is rather conventional, composed of only RE-TM intermetallic compound phases. Type $B$ is a mixture of RE-TM intermetallic compounds and elemental RE phases. Type $C$ is a mixture of RE-TM intermetallic compounds, elemental RE and TM alloys phases.

Generally, Types B and C produce films with superior compositional uniformity, while Type A exhibits, better compositional stability at long sputtering times[1]. The present study, however, emphasizes that a Type B target exhibits excellent performance according to both of these criteria when used in conjunction with a properly designed cathode.

Table I Constitution of targets.

\begin{tabular}{ll}
\hline Type & \multicolumn{1}{c}{ Phase } \\
\hline A & Intermetallic compounds \\
B & Intermetallic compounds and elemental-RE \\
C & Intermetallic compounds, \\
& elemental-RE and TM-alloys \\
\hline
\end{tabular}

Table II Target characteristics and sputtering conditions.

\begin{tabular}{|c|c|c|c|c|c|c|c|c|c|}
\hline \multirow{2}{*}{$\begin{array}{c}\text { Sample } \\
\text { No. }\end{array}$} & \multirow{2}{*}{$\begin{array}{l}\text { Target } \\
\text { type }\end{array}$} & \multicolumn{4}{|c|}{ Target composition(at\%) } & \multirow{2}{*}{$\begin{array}{c}\text { Target } \\
\text { diameter }\end{array}$} & \multirow{2}{*}{$\begin{array}{c}\text { Target } \\
\text { thickness }\end{array}$} & \multicolumn{2}{|c|}{ Sputtering conditions } \\
\hline & & $\mathrm{Tb}$ & $\mathrm{Fe}$ & Co & $\mathrm{Cr}$ & & & Ar pressure & Sputtering power \\
\hline 1 & $A$ & 29.0 & bal. & 8.0 & - & $203 \mathrm{~mm}$ & $3 \mathrm{~mm}$ & $1 \mathrm{mtorr}$ & $1 \mathrm{~kW}$ \\
\hline 2 & A & 27.2 & bal. & 5.6 & 3.0 & $152 \mathrm{~mm}$ & $6 \mathrm{~mm}$ & 6 mtorr & $0.5 \mathrm{~kW}$ \\
\hline 3 & $\mathrm{~B}$ & 19.8 & bal. & 7.9 & - & $203 \mathrm{~mm}$ & $7 \mathrm{~mm}$ & 2 mtorr & $1 \mathrm{~kW}$ \\
\hline 4 & B & 23.5 & bal. & 8.1 & - & $203 \mathrm{~mm}$ & $3 \mathrm{~mm}$ & $2 \mathrm{mtorT}$ & $1 \mathrm{~kW}$ \\
\hline 5 & B & 29.5 & bal. & 7.9 & - & $203 \mathrm{~mm}$ & $3 \mathrm{~mm}$ & 2 mtorr & $1 \mathrm{~kW}$ \\
\hline 6 & $\mathrm{C}$ & 20.0 & bal. & 8.0 & - & $203 \mathrm{~mm}$ & $7 \mathrm{~mm}$ & $2 \mathrm{mtorr}$ & - \\
\hline 7 & - & & Aluminum & & & $203 \mathrm{~mm}$ & $5 \mathrm{~mm}$ & - & - \\
\hline
\end{tabular}




\section{EXPERIMENTAL PROCEDURES}

Alloy Targets were fabricated by hotpressing metallic powders which were produced by the reduction and diffusion(RD) method[2,3]. The bulk compositions of all targets are listed in Table 2.

In the case of the Type B targets, the ratio of RE in the intermetallic compound to RE in the elemental form was 4:6. The size and thickness of all targets are also listed in Table 2. The composition was measured by EPMA at several points along the diameter of all films.

Sputtering with the new cathode (Inline Disk Sputtering Machine ILC-3100 by Anelva corporation) was performed at a target-to-substrate distance of $145 \mathrm{~mm}$. With the exception of target \#2, which was sputtered onto a revolving substrate, all sputtering was done under static conditions.

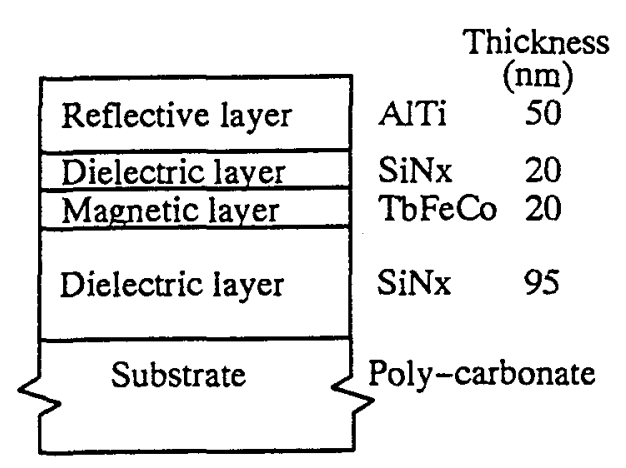

Fig. 1 Quadrilayer structure of medium in the present study.

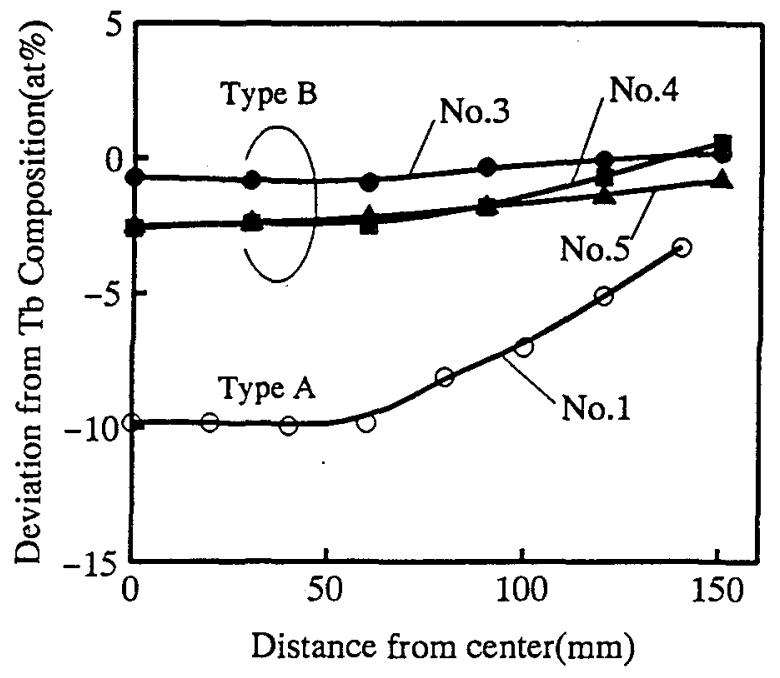

Fig. 2 Deviation from $T b$ content of target, as a function of position on film.
Table III Conditions of CNR measurements.

\begin{tabular}{ll}
\hline Laser wavelength & $830 \mathrm{~nm}$ \\
Read power & $1.5 \mathrm{~mW}$ \\
External magnetic field & $2000 \mathrm{e}$ \\
Revolution & $1800 \mathrm{rpm}$ \\
Bit length & $0.76 \mu \mathrm{m}$ \\
\hline
\end{tabular}

Magnetic fields were measured with a Hall-effect Gauss-meter, using a $4 \mathrm{~mm} X 1 \mathrm{~mm}$ probe. The horizontal and vertical components of the magnetic field were measured at $1.5 \mathrm{~mm}$ and $0.5 \mathrm{~mm}$ above the target surface, respectively.

For the carrier to noise ratio(CNR) measurement a quadrilayer was constructed upon a Poly-carbonate substrate as shown in Fig. 1. The conditions of the CNR measurement are listed in Table III. The disk used for this measurement was produced by substrate revolution.

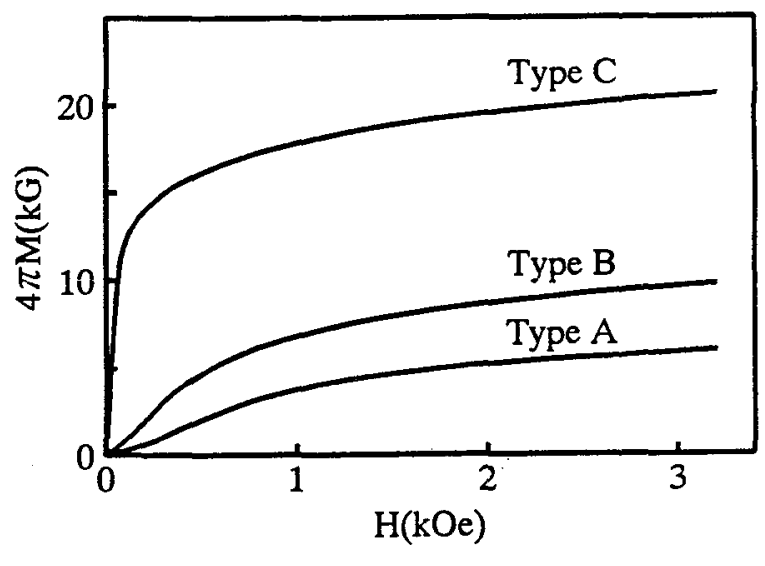

Fig. 3 Magnetization curves for Type A, B and C targets.

\section{RESULTS AND DISCUSSION}

\section{(1) Uniformity and stability of films}

The compositional uniformity of films obtained from all targets are shown in Fig. 2, in terms of deviation from $\mathrm{Tb}$ content of the targets. It can be confirmed that the uniformities obtained from all targets of Type B for various compositions are superior to that of the Type $A$. The Type $C$ target was not sputtered successfully, due to its small leakage field. As shown in Fig.3 the spontaneous magnetization of Type $C$ is $17 \mathrm{kG}$, in contrast with $3 \mathrm{kG}$ and $5 \mathrm{kG}$ for Types $\mathrm{A}$ and $\mathrm{B}$, respectively. Such difference in uniformity may be explained by the emission angle distribution of the 


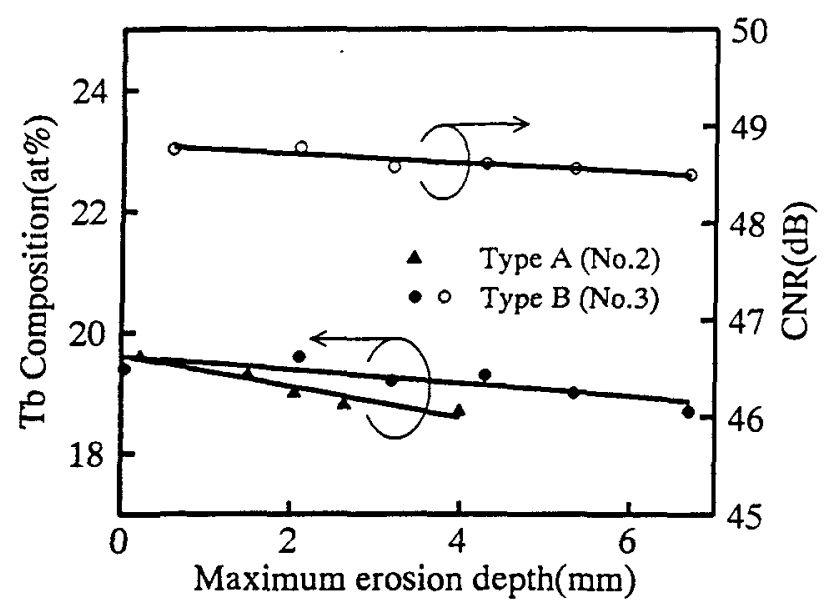

Fig. 4 Film composition and CNR as a function of sputtering depth for Type A and B targets.

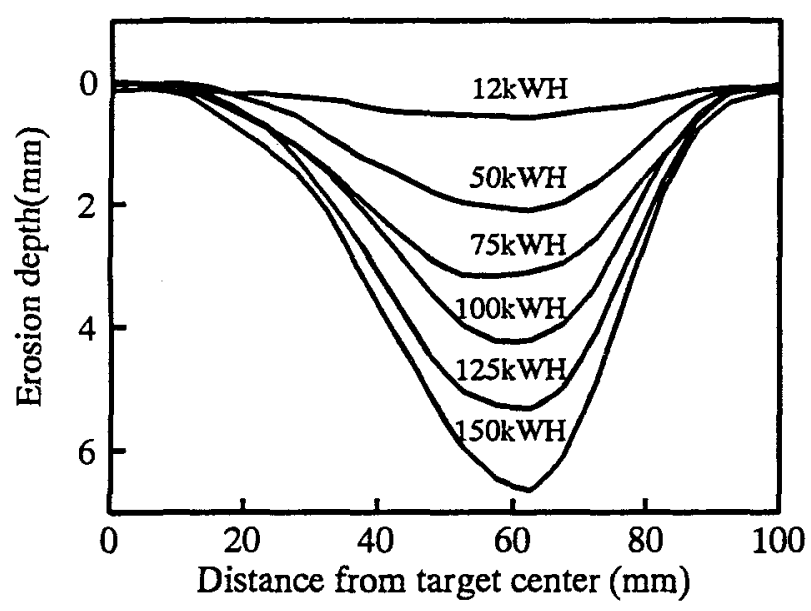

Fig. 5 Erosion profiles of Type B target, for various values of accumulated sputtering power.

various phases in the target. Since the emission angle distribution of the elemental RE phase, may be quite different from that of the intermetallic phase, it can complement the emission angle distribution from the RE-TM intermetallic compounds. Studies are presently underway to confirm or deny the validity of this interpretation.

The present magnetic field configuration improves the compositional stability of Type B targets, while maintaining the compositional uniformity of the films produced. The composition of films sputtered from Type $A$ and Type B targets are plotted as a function of maximum erosion depth in Fig. 4. The data for the Type
A target was obtained by revolving the substrate in order to compensate for the inherent lack of film uniformity associated with Type A targets. The data for Type B targets were measured at the film center. While both targets exhibit very good compositional stability, it is clear that Type B is much better than Type A, in spite of the fact that the data for Type B was obtained without substrate revolution or rotation. The Type B target also possess excellent stability for a disk produced by rotation and revolution. The first film sputtered shows a CNR value of $48.8 \mathrm{~dB}$, and the final one, $48.5 \mathrm{~dB}$, with regard to $\mathrm{CNR}$. This improvement in compositional stability can be conjectured to result from the improved erosion pattern.

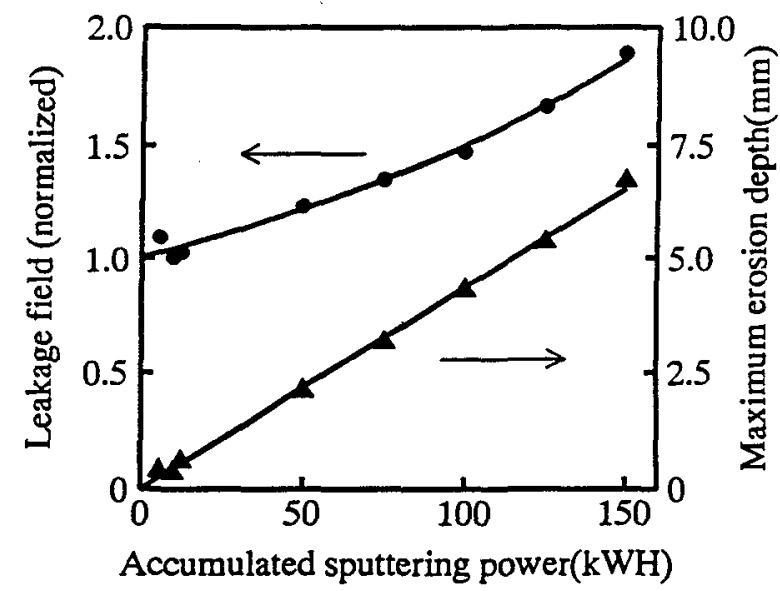

Fig. 6 Magnetic leakage field(normalized) and maximum erosion depth as functions of the accumulated sputtering power.

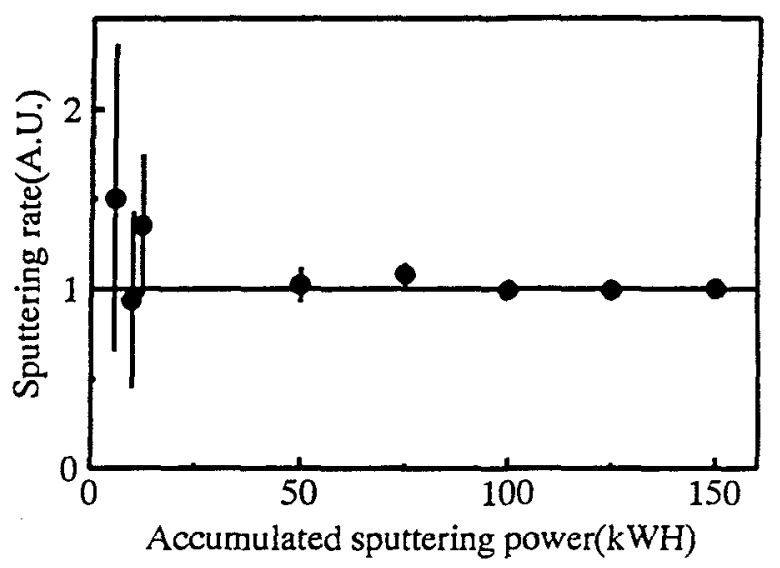

Fig. 7 Sputtering rate for Type B target.

(2) Erosion of target

The erosion patterns of the Type B targets are 


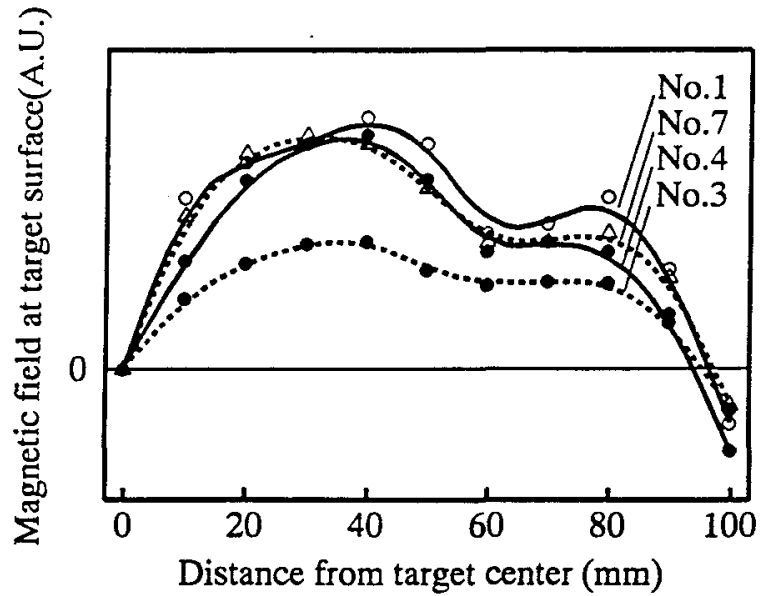

Fig. 8 Horizontal component of the magnetic field at the target surface for Type A and B targets, compared with a non-magnetic(Al) target.

shown in Fig.5 for various values of the accumulated sputtering power. After sputtering to a maximum erosion depth of $7 \mathrm{~mm}$, the Type $B$ targets exhibit the wide erosion pattern shown, corresponding to a total emission of 45 vol\%. Compared with the total emission obtained from the conventional cathode in the previous paper[1], the new cathode produces an increase of more than 15 vol\%. The shape of the erosion profile is independent of sputtering time and all of the curves differ by only a scaling factor. As shown in Fig. 6, both the erosion depth and the leakage field increase monotonically with sputtering time,(The value of the leakage field reported in this figure is that measured at the point where the vertical component of the magnetic field is initially zero).
Interestingly, the erosion depth curve exhibits reasonable linearity for all ranges of the accumulated sputtering power. Integrating the total volume eroded, we obtain the sputtering rate shown in Fig. 7. Except for the first several points which have a large error, it can be confirmed that the sputtering rate is quite constant. It should be noted that the sputtering rate, at this point, is independent of time, in spite of the fact that the field strength continually increases. Since the center of the sputtering plasma is located at the point where the vertical component is zero, it can be inferred that the sputtering rate does not depend upon the field strength at the target surface.

\section{(3) Magnetic field distribution}

The magnitude of the horizontal component of the magnetic field at the target surface is shown in Fig. 8, as a function of radial position, when the new cathode is used with targets No. $1,3,4$ and 7 . The last sample(No.7), is a non magnetic (Al)target, for purposes of comparison. Using the Type B target of $3 \mathrm{~mm}$ thickness the field strength at the surface approximates that of the non magnetic target. Even for a target of $7 \mathrm{~mm}$ thickness, the magnetic field remains about half that of the nonmagnetic target.

\section{(4) Field analysis of magnetic circuit}

The magnetic field at the surface of the three targets was obtained by the finite element method for a conventional cathode model. The calculated field distributions $1.5 \mathrm{~mm}$ above the surface are shown in Fig. 9 for Types A, B and C. In this model the target is $80 \mathrm{~mm}$ in diameter by $5 \mathrm{~mm}$ in thickness, and the magnets are $\mathrm{SmC05}$. The peak values obtained for the horizontal field component are in the ratio 5:4:1 for Type A, B and C targets, respectively. The maximum flux densities in the interior of Type A, B and $C$ targets are 4,5 and $14 \mathrm{kG}$, respectively. Therefore, Type $A$ and $B$ targets perturb the field so slightly that they can be
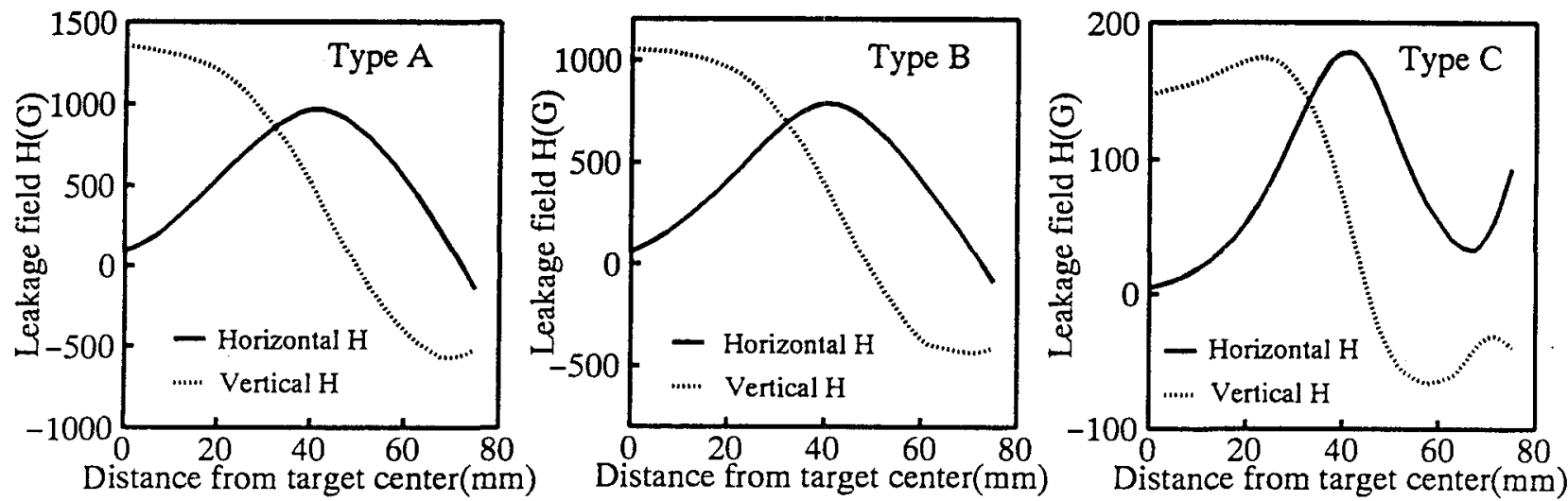

Fig. 9 Magnetic field distributions for Types A, B and C. 
used even in weak field cathode structures. The Type $C$ targets, on the other hand, confine the magnetic field, i.e. they play a role of a magnetic shield.

\section{CONCLUSIONS}

The major conclusions which can be drawn from the present investigation are as follows: 1.) Type B targets possess superior performance characteristics, i.e. compositional uniformity, compositional stability and waste ratio. 2.)The sputtering rate (at least under the present conditions) is independent of the magnetic field strength. 3.)Low magnetization targets provide for greater flexibility in cathode design, since they are essentially transparent to the magnetic field.

\section{ACKNOWLEDGEMENT}

The authors would like to thank Dr T. Satoh and Dr E. Boltich for their many useful discussion and $\mathrm{Mr} \mathrm{S}$. Hamada for performing the computer simulation.

\section{REFERENCES}

[1] T.Nate, T.Morimoto, S.Endoh and K.Oka, IEEE Trans. Magn., MAG-24, 2443(1988).

[2] R.E. Cech, J. Metal, 26, 32(1974).

[3] K.Satoh, K.Oka, J.Ishii and T.Satoh, IEEE Trans. Magn., MAG-21, 1979(1985). 